\title{
Coulisses
}

Revue de théâtre

12 | Printemps 1995

Varia

\section{La mise en spectacle de l'amour-passion dans Partage de midi}

Michel Autrand

\section{OpenEdition}

1 Journals

Édition électronique

URL : http://journals.openedition.org/coulisses/3278

DOI : $10.4000 /$ coulisses.3278

ISSN : 2546-9460

Éditeur

Presses universitaires de Franche-Comté

\section{Édition imprimée}

Date de publication : 1 mai 1995

Pagination : 16-18

ISSN : 1150-594X

\section{Référence électronique}

Michel Autrand, "La mise en spectacle de l'amour-passion dans Partage de midi », Coulisses [En ligne], 12 | Printemps 1995, mis en ligne le 15 mars 2019, consulté le 27 octobre 2019. URL : http:// journals.openedition.org/coulisses/3278; DOI : 10.4000/coulisses.3278

Ce document a été généré automatiquement le 27 octobre 2019.

Coulisses 


\title{
La mise en spectacle de l'amour- passion dans Partage de midi ${ }^{1}$
}

\author{
Michel Autrand
}

1 Reprenant la manière de L'Échange $e^{2}$, Claudel noue d'un nœud passionnel étroit un petit nombre de personnages, un simple quatuor, mais un quatuor en déséquilibre, où domine l'élément masculin : une femme seule face à trois hommes, son mari et deux amants. C'est, comme on l'a remarqué, le modèle d'Hernani réduit à l'essentiel. Et ces quatre personnages ont chacun double visage. Un visage réaliste: celui de fonctionnaire colonial et d'aventuriers dans la Chine des Boxers, celui aussi d'hommes et de femme qui ont vécu, qui ont dépassé la trentaine. Plus, chez eux, d'exaltations juvéniles et légères; des lames de fond, au contraire, définitives, avec à peine ici ou là un soupçon d'amertume ou d'ironie. La femme est mariée, sexuellement heureuse, et, comme Phèdre, elle est mère : elle est, en tant que femme, accomplie, réalisée. La surprise de l'amour n'en aura ainsi chez elle que plus de pureté et d'intensité. Le temps des apprentissages est passé. Ysé aimera d'emblée au sommet de l'amour. Car tous sont bien, pour reprendre le mot d'Amalric à l'acte III, non « des créatures de rêve, mais de réalité ». Et pourtant ils ont tous aussi une autre face venue, elle, de la mythologie symboliste et de la mythologie proprement claudélienne. Image de l'éternelle femme, avec son nom si proche de celui d'Yseult ${ }^{3}$, Ysé continue Mélisande et Lâla, tout comme Mesa sans doute le roi biblique de La Légende des siècles ${ }^{4}$. Dans chaque personnage, et même dans De Ciz, vit ainsi, plus grand que lui, quelqu'un - pourrait-on dire en paraphrasant un vers célèbre de Vers d'exil - qui est en lui plus lui-même que lui. Double face, double jeu, théâtralité accrue, redoublée, essentielle: il y a là une donnée structurelle, plus originale qu'on ne pense, qui va colorer toutes les manifestations de l'amour-passion dans la pièce.

2 Ce dernier n'est ni un ingrédient ni un aspect de l'ensemble. Il n'y a pas, comme dans Polyeucte, drame profane et drame sacré interférant à un moment donné. Ce qui est sacré, ici, c'est le drame profane tout entier. Dieu est lecture de cet unique drame, Dieu n'a rien d'autre à faire qu'à lire ce drame qui est donc à lui seul toute la pièce. Au cœur de chacun des trois actes, une grande scène d'amour entre les deux héros: l'aveu à 
l'acte I, la prise à l'acte II, l'étreinte ultime à l'acte III, avec en contrepoint chaque fois trois autres scènes d'Ysé amoureuse en compagnie de De Ciz à l'acte II et d'Amalric aux actes I et III. Rien d'autre que l'amour ne peut vraiment prendre corps dans la pièce : même la fièvre colonisatrice d'Amalric risque toujours de faire effet d'ornement décoratif avant le sensuel coucher de soleil qui termine l'acte I. On aurait tort, d'ailleurs, car il y a tout autant d'érotisme dans ce désir avide de l'homme blanc ${ }^{5}$, et de cette passion du globe Rodrigue plus tard se souviendra. Tout en fait s'ordonne en fonction du désir. [...]

Dans le début de l'acte I nous est d'abord montré le monde ennuyé des êtres sans amour dont Ysé fait une évocation ironique. Quand l'amour y surgit, il est aussitôt l'absolu, l'irrécusable, et, un court moment du troisième acte mis à part, les trois scènes d'amour de Mesa et d'Ysé ne consistent très remarquablement qu'en accord et approfondissement au sein d'une extase fondamentale. Si bien qu'à l'impétuosité de la passion se lie toujours chez les amants une lucidité sur eux-mêmes aussi précise que celle dont fait preuve par exemple la Phèdre de Racine. Non une perte dans l'absolu de l'amour, mais avec lui un affrontement permanent. Très vite, et du côté de l'homme seulement, les obstacles apparaissent. Externes, comme le mariage d'Ysé ou la révolte des Chinois, ils ne comptent guère, mais les obstacles internes sont plus graves que la passion débusque tour à tour. C'est sans doute d'abord un recul devant l'image de la mère ou plutôt de la sœur innommée, attitude que la critique psychanalytique dénonce devant les étranges moments d'hésitation que connaît Mesa en présence de la femme ${ }^{6}$. Plus net encore l'égoïsme ou mieux le désir de non-dépossession chez un héros qui entend " ne pas tout donner $»^{7}$. Mais l'obstacle majeur en définitive est la force mystérieuse qui n'est d'abord que «Il » et qui prend ensuite le nom de « Dieu ». Ce Dieu toutefois, qu'après l'avoir aimé dans Tannhäuser Claudel déplorait de ne plus trouver dans Tristan, ne revêt aucune des formes scéniques habituelles : jamais il ne devient ni une personne ni une soutane ni un livre ni même un objet. Il n'existe que dans le discours des personnages et des forces naturelles. À un moment, cependant, il lui arrive de prendre une réalité scénique intense, lorsque Mesa, rompu, dans son Cantique, s'adresse directement à lui. Mais le coup de théâtre est alors que, loin que Dieu apparaisse comme l'obstacle à l'amour d'Ysé, c'est lui qui a, Mesa le reconnaît, suscité cet amour à Mesa pour l'amener à un amour véritable de lui-même, Dieu. L'amourpassion pour la divinité prend ici le relais, devient la raison d'être et la tension permanente de l'amour humain. L'image scénique, dans cette extrémité, risque de s'épuiser à essayer de traduire les italiques dont Claudel a gratifiées ce chant de Mesa. Cette version mystique de l'amour-passion semble impliquer l'immobilité. La musique de la voix et l'élargissement du décor auront charge à eux seuls de dire la dimension intime et cosmique de l'Amour.

4 Mais ce moment lui-même n'est pas le dernier de la pièce, puisque Ysé revient pour une ultime scène d'amour qui pose un problème tout à fait spécifique. Cette scène peut évidemment être jouée dans le même registre que les scènes précédentes, l'attente à deux de l'explosion et de la mort exaltant naturellement les amants. Il ne serait cependant pas non plus radicalement impossible d'y voir un moment onirique, un adieu délirant de l'auteur, qui ne ferait revenir Ysé que dans le rêve ébloui de Mesa. Mais le plus intéressant consisterait à unir ces deux interprétations, et Claudel luimême, dans un texte il est vrai tardif ${ }^{8}$, mais rétrospectivement très éclairant, nous en donne le moyen. Il écrit à Jean-Louis Barrault : 
L'Esprit... oui... mais égoïsme, avarice, dureté, sécheresse, orgueil, ce que le bon Dieu déteste le plus au monde... La Chair ? C'est vrai, elle apporte l'autre, mais avec l'autre, le besoin de l'autre, l'esclavage de l'autre, - et la constatation d'une impossibilité de l'atteindre, quelque chose qui ressemble pas mal à l'Enfer. Mais audessus de la chair, il y a la superchair - il y a le cœur qui est aussi de la chair, ce cœur qui nous a faits et qui en sait plus long que nous. Dieu ne l'a mis dans notre poitrine que pour trouver son écho dans la poitrine d'un autre. C'est ce cœur qu'elle a eu comme ça l'idée de rapporter à ce misérable et abandonné. Elle allait partir, elle allait se laisser emporter par le courant, je ne sais où, au diable. Mais tout à coup elle a eu cette espèce de coup de soleil, un coup de soleil étoile qu'on lui a administré. Et elle est revenue, ne sachant pas trop ce qu'elle faisait. Elle sait seulement qu'elle est la plus forte. Ne fais pas le malin, débris ! C'est moi qui suis la plus forte. Avare! le sens-tu, ce cœur qui bat? Ce n'est pas seulement l'être que je suis venue t'apporter avec lui, c'est la raison d'être.

L'amour-passion, dans la scène finale, relèverait ainsi de la «superchair ", d'une humanité tenant à la fois des limbes et des corps glorieux, où s'unissent non seulement le rêve et le réel, mais l'esprit et le corps, l'amour humain et l'amour divin dans une passion théâtrale unique, dont la mise en spectacle de nos jours encore constitue une audace-limite et lance aux metteurs en scène un véritable défi.

L'Abandon, Camille Claudel

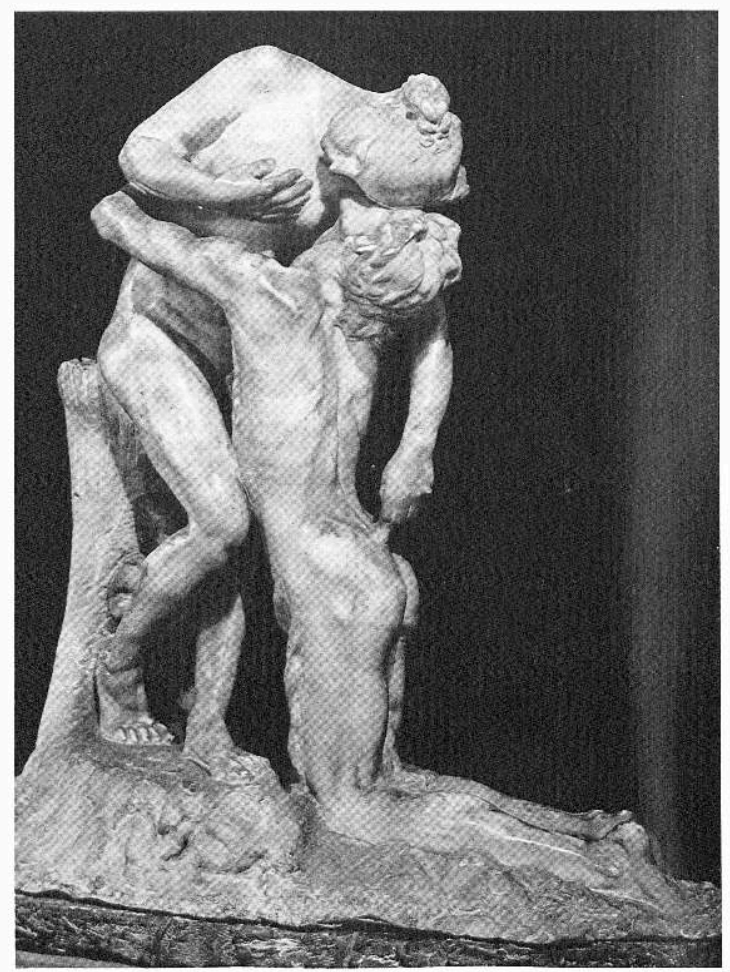




\section{NOTES}

1. Extrait de L'Information littéraire, janvier-février 1985.

2. Lettre de Claudel à Gabriel Frizeau du 6 septembre 1905.

3. Parmi les hypothèses proposées pour le nom d'Ysé, on notera celle de Moriaki Watanabé : «Le nom d'Ysé : le mythe solaire japonais et la genèse du personnage » in R.H.L.F., $\mathrm{n}^{\circ} 1$, janvier-février 1969.

4. Voir Eugène Roberto, «Mesa » in Géographie poétique de Claudel, Cahier Canadien Claudel $n^{\circ} 4$, Editions de l'Université d'Ottawa, 1966, p. 195-204.

5. Beaucoup plus, me semble-t-il, qu'il n'y a d'esprit de colonisation dans l'amour-passion luimême. Voir sur ce point Anne Ubersfeld lit Partage de midi, Temps actuels, 1981.

6. Voir Michel Malicet, Lecture psychanalytique de l'œuvre de Claudel, les Belles Lettres. 1979, tome I, p. 98.

7. Michel Lioure, L'Esthétique dramatique de Paul Claudel, Armand Colin, 1971, p. 281.

8. Lettre du 7 avril 1950 